\title{
THE EFFECTS OF L1 OVERUSE IN L2 LEARNING: EVIDENCE FROM THREE CASE STUDIES
}

\author{
Rafael Filiberto Forteza Fernández \\ Assoc. Prof. Ph.D., Ural Federal University, Russia, rafaelforteza@gmail.com
}

\begin{abstract}
Foreign language teaching based on the mother tongue has been the traditional vehicle of instruction in Russian classrooms from the primary to high school levels, at language schools as well in teacher-formation at pedagogical institutes as is evidenced by the results of information obtained through interviews to teachers, observation of the students' in-class behavior and revision of textbooks produced by national authors. Grounded on data (transcripts, essays, and real class examples) gathered during five years, the paper examines the effects of excessive mother tongue use in foreign language classrooms in Ekaterinburg, Russia. The three case studies as well as other classroom instances reported and discussed here illustrate how previous educational experiences have modeled the students' learning style to such extent that limited progress in communicative skills in English and Spanish is achieved due to their constant reference to the Russian language system, despite having had enough controlled practice and performed well in the controlled application stages of the learning process. As a result, this varied in its manifestations perceived need on the part of the student to recur to Russian to communicate in the L2 originates time-consuming psycholinguistic processes that affect accurate and fluent language production. The paper also advances ideas on how to counteract this problem in class as well as the areas that require more attention on the part of the teacher. The study concludes that though the more than a century-old teaching dilemma concerning the role of the L1 in L2 foreign language pedagogy is still far from been resolved; one thing, however, is clear: excessive translation from and to the native language hampers greatly the outcomes of the instructional process.
\end{abstract}

Keywords: Mother Tongue; Foreign Language; Translation; Psycholinguistic Processes; Accuracy; Fluency

\section{INTRODUCTION}

After having taught for thirty years, first under the "strict" banning of MT use in EFL and after the introduction of CLT in Cuba in the early 1980s when judicious reference to Spanish in the teaching of foreign languages was generally accepted, five years ago the writer was shocked to experience since his very first lesson in Russia, students who, no matter their language level, constantly resorted to the MT, relied on online translators or bilingual dictionaries and asked each other about the translation of a language item while carrying out any type of exercise. Even if a new word was taught using visual means, the student invariably recorded the word with its translation on the notebook. At the same time, numerous episodes of code switching during performance were observed; in each of these the student would ask: 'How can I say ...?' evidencing their output was based on translation from the MT. Despite all advice not to do any of those things, the students kept on doing the same, proof that this was the way in which they mostly deal with foreign languages challenges. 
To the author's dismay, a similar situation was found at a pedagogical university. While expressing his point of view about the books and how the lessons were to be developed, the author was bluntly told by the head of the department and principal professor of ELT methodology, "Translation is the only way to develop logical thought." An assertion whose origins I still do not know and did not question at that moment for fear to get into trouble. Obviously, all translation exercises, except those from Russian into English because it was a mandatory final test question, were discarded. It was then that recording the students' performance after translation and communicative output activities for follow-up correction began, a practice kept on to the present accounting for around forty hours of interlanguage samples. Many of them reveal that after having done well during lexicogrammar controlled practice, many learners do not seem to be able to transfer to communication what they, supposedly, have learned.

A thorough check of the foreign-language section in Ekaterinburg libraries revealed $96 \%$ of national authors' textbooks for sale rely on explanations in Russian in their attempt to teach English, Spanish, German, Italian or any other major language. Other features common to all of them are translation and interpretation of sentences, usually related to a specific grammatical structure, and short passages, generally comprising previously studied language as well as vocabulary lists with the MT equivalent. The phrase "New Method" is quite often included in the title. Similarly, those officially used in teacher-formation echo the same concepts though L1 use is slightly lower. Apparently, the principle behind such methodology is that once the student has mastered the foreign language lexicogrammar, they should be able to give the equivalent in the mother tongue. However, no guidelines as how to translate or interpret are ever given. Not surprisingly, the teaching style is perpetuated in the future language professionals. Unfortunately, this is also imprinted in the learner's learning style for they will, all the time, look for support from the MT no matter the level achieved.

The present paper is aimed at finding out the theoretical bases upon which such traditional teaching practices are founded, conceptualizing the potential psycholinguistic processes occurring during foreign language production of students exposed to L1 overuse in previous educational experiences; their effects on language progress and proficiency and how to manage with some degree of success such situations in class.

\section{REVIEW OF LITERATURE}

The use of translation as a teaching technique in foreign language teaching in Russian classrooms seems to have its root in the Soviet Conscious Practical Method, dating back to the early years of the revolution (Karpov and Miroliybov, 1957). In the 1960s, as a result of experimentation and investigation in educational psychology and methodology, the method underwent further development which in terms of the conscious approach meant "...that language learning implies comprehension of a linguistic phenomenon of language material by the pupil usually [through] the medium of the native language..." as opposed to "mechanical learning through repetitive drilling" (Rogova, 1975:40). Apparently, research carried out by two psychologists had strong impact on configuring the future of L2 pedagogy in the country.

According to the same author (op.cit.:42-43), in the teaching of the L2 grammar Artemov's research favored inductive teaching of rules in the form of algorithms, while Belyaev's supported the above and introduced the idea that "Only language practice supported by theory can develop language habits and skills in a desirable direction." Derived from the above, the method or approach-Rogova uses both concepts indistinctivelypresupposed the use of the MT "...to establish direct associations between concepts and their means of expression in the second language." Although a potential transition period to thinking in the L2 is acknowledged, L1 use is considered advisable in case the student needs help in acquiring new knowledge. In addition, while conscious learning clearly opposes behaviorist psychology, such acquisition is largely based on the student's voluntary and involuntary memory processes, imagination and will power for the memorization of words, phrases, sentence patterns, structures and kept in long-term memory ready to be used. The principle of consciousness assured two things: more formal teaching of grammar...and ... greater emphasis upon the value of the mother tongue as the basis for teaching the foreign language, though translation was discouraged (Glyn, 1962).

However, in the teaching of vocabulary, two techniques the direct method (realia, pictures, the context) and translation were recognized making no distinction as to their usefulness. This allowed teachers to use the second as the fastest, most economic one as a result of which the student was given the false impression that there are exact one-to-one equivalents between words in the L2 and their native language. On the other hand, translating was recommended as one of the techniques to use new learnt grammar creatively in an attempt to "accumulate correct sentence patterns in the pupils' memory which they can reproduce whenever they need these for speaking or writing" (op. cit.:148). 
In short, at taking a clearly unambiguous position in three central issues in language learning: the L1-L2 connection, the explicit-implicit option and the code-communication dilemma and merging them with the results of domestic research constrained by the state's philosophy and political objectives, the Soviet pedagogical approach to L2 teaching gave birth to kind of a hybrid where objectives and contents of the teaching process were in contradiction with its methods and techniques. That is, an emphasis on grammar theory and translation hardly leads to an ability to communicate in the L2. In a historical account of Soviet foreign language pedagogy in Ukraine, and by extension to the rest of the union, Stepukina (2013) admits that the excessive use of theory and translation led to the domination of the mother tongue in foreign language classes.

As traditions do not fade away so easily, remnants of the Conscious Practical Method may still be observed in teacher-formation (Solovova, 2006) and the teaching of foreign languages in general (Litvinov, 2004; Zikova, 2006; Ivanova, 2010; Nuzhdin, Marin \& Martin Lora, 2003). These may explain to some extent, at least in the case of English, historically poor language learning outcomes as evidenced by Russia's ranking: 32 $2^{\text {nd }}$ in 2013 and $36^{\text {th }}$ in 2014 among 63 countries in the English Language Proficiency Index in 2013 and 2014 respectively, though the measurement is usually criticized because of the way the data is gathered. In the region where the author works, the Urals, a very low level score (46.54) was obtained last year. In no way the above means there are no very competent English as second language speakers in Russia.

The opinions on the use of the L1 in the L2 classroom are divided. On the one hand, Malmkjaer (1998) argues translation is unnatural and takes valuable time that could be used to strengthen reading, writing, speaking and listening at the time it misleads and prevents the students from thinking in the L2, produces interference and is independent and radically different from the aforementioned competence defining skills. On the other, most practitioners consider the use of MT in the foreign language classroom no longer a taboo. Based on research results, El-dali (2011) points out that confining the lesson only to the L2 may be done at the expense of understanding and intelligibility; "Mother tongue use", he asserts, "does not mean wasting time that can be better used for providing maximum exposure to the foreign language..." as well as a good tool if used adequately (Dagiliene, 2012). Mutlaq Al-zu'be (2013), for instance, reports on its positive direct impact on an individual's writing skills besides improving vocabulary and Mahmoud (2006) as a post-reading procedure because of the many opportunities it offers to evaluate the main and specific ideas in an authentic text as well as problematic areas, which demand further attention in class. In other words, the consensus today is communicative language teaching does not mean complete rejection of familiar techniques such as translation to promote communicative competence.

Granted, the L1 sets the background context for L2 learning (Carroll 2008), which can be a help or a hindrance. In Piagetian terms, this means L2 assimilation processes take inevitably as reference the L1. However, as accommodation processes follow or are carried on simultaneously, the extent a learner is able to fit the L2 in previous cognitive structures as a different system and use it independently in communication may largely depend on the amount of L1 reference during assimilation. In other words, informed decisions on L1 use in the classroom must answer at least: What to translate or interpret: $A$ sentence or a text; orally or in writing; when to do it: at what stage of the learning process; and most important of all, what benefits it will bring about and how it complements and fits harmonically with the rest of classroom activities.

The potential to realize the L2 more or less independently of the L1 depends, in the author's opinion, on two variables: first, the instructional method, seen as what the teacher does to facilitate and foster learning and second, learner factors, understood as individual variables-age, attitude, motivation, previous learning experience--having an incidence in the same process. Because all teaching learning situations and learners are different, no specific formulas can be prescribed. Nonetheless, variety in instructional method and approach seem also to have a role in the formation of learning styles. On this issue, Petrina asserts that "If we vary our methods, we have learned, we accommodate a wider range of learning styles than if we used one method consistently." In terms of the L1-L2 connection, this means that the more L1 is used in class, the more the student will recourse to it in communication. In addition, recent research (Rogowsky, Calhoun \& Tallal, 2015) has shown that rather than accommodating the instructional method to pre-conceived learning styles, it is advisable to strengthen the learner visual skills in language comprehension. By conceptual extension, the same could be said about other language skills and in teaching the discrete points of language. In other words, such variety implies different ways to present practice and apply new content as well as the subsystems of the L2 instead of following the schematic dogmatic logic and procedures of a single method.

As to the explicit-implicit option, Forteza (2015 - forthcoming) advocates an eclectic approach to the teaching of lexicogrammar where the student is taught that choice of form to construct meaning is context constrained. Originated for ELT--and later also applied to teach Spanish--as a response to the very characteristics of Russian foreign language students and learning styles as well as his limited command of their L2, the CMFapproach, as the author has called it, is the result of a multi-disciplinary point of view in the application of 
theory and research (Ur, 1988; Celce-Murcia, 1991; Celce-Murcia \& Larsen- Freeman, 1999; Cook, 2008; Nunan, 1988, 2015; Larsen-Freeman, 2009; Halliday, 1985; and Hassan, 2009) as well as expertise achieved through more than thirty years of classroom practice. The approach has helped to fill in the existing gap between the intake of the L2 forms and how they are actually put into meaningful-focused communication. To achieve such outcome the learner is to be given enough opportunities to touch and feel the new items before being led to interiorize, produce and finally fit them into their cognitive schemas creating their own interlanguage, at the time it discourages translation and excessive rules. In all this process, feedback plays different roles and takes different forms, each of which is determined by the particular assimilation level, individual student and classroom situation. Though the CMF-approach seems to be a feasible tool to improve language teaching, it still must undergo the necessary natural transformations and adaptations to the everchanging teaching environments in which it is put into practice.

The CMF-approach complies with the assumption that during "receptive practice, learners pay attention to the targeted linguistic data in the input while processing the grammatical information substantially enough to be capable of recognizing, interpreting, and/or producing such forms or structures after exposure" (Leow, 2007:22). Research cited by the same author (op. cit::36-42) confirm that other factors such as attention, elicitation procedures, awareness and complexity of linguistic items together with such type of practice lead to efficient L2 data processing fostering internalization and increasing the potentials for accurate, fluent output. Therefore, L2 linguistic items, such as words are not stored in the form of bilingual dictionary entries nor are empty grammatical patterns governed by hundreds of rules and exceptions better learnt in the form of algorithms ready to be used for communication as the Conscious Practical Method intended.

From a psycholinguistic point of view, lexicon is organized in semantic networks of interconnected elements in hierarchical form (Collins and Quillian, 1969, 1970, 1972; cited by Carrol, op.cit.: 110-115). Based on the principle of cognitive economy, Collins and Loftus (1975; ibid.) expanded the model later by explaining that some nodes are to be more accessible [for retrieval] in relation to such factors as frequency of usage and typicality where "activation begins at a single node and then spreads in parallel throughout the network, attenuated over distance, "thus ensuring that closely related concepts are more likely to be activated than distant [ones]." Moreover, Carroll stresses that the complexity of factors influencing L2 lexical choice also range from phonological structure, syntactic and morphological structure to the existence of semantically related words and a word's alternative meanings. Besides, because the $L 2$ learners' lexical representations do not have a strong form-meaning connection the resulting semantic access is achieved through translation except in cases of high levels of proficiency (Duyck \& Warlop, 2009). Consequently, an MT over dependent learner's L2 lexicogrammatical choice will be more severely affected the more it is the result of L1 translationbased priming.

Because of its heuristic potential, Levelt's model for language production (1999), summarized below, has been chosen as the tool to explain the MT over dependent learner psycholinguistic processes for interlanguage production during unprepared communicative output.

The model is composed of four different stages. In the first, conceptual preparation, the speaker generates a non-linguistic pre-verbal message consisting of lexical items. That is, those which can be expressed through words. In the second, grammatical encoding, syntactic words, lemmas, are activated by the lexical items.

Their selection makes the syntactic frames available that should correspond to the semantic functions and arguments in the message. In grammatical encoding, the speaker uses this lexical syntactic information to build up the appropriate syntactic pattern, the 'surface structure'. And this is roughly done incrementally, that is 'from left to right'. This completes the processing of the first core system. (Op. cit.:88)

The third stage, morpho-phonological encoding, starts with the activation of the lemma form code immediately after selection. That is, the speaker accesses the selected lemma's morphological and phonological composition which is the basis to generate a word's syllabication in connected speech. A phrase is syllabified according to its surroundings words. For instance, have is phonologically realized differently in you-have than in the phrase you-shoul-dve. The phonological score of an utterance is built up incrementally following the requirements of grammatical encoding. It is here where words and phrases take their final shape as well as where word and sentence stress and intonation as well as pitch are conceived.

In the final stage, phonetic encoding, such 'phonological score' must spark incrementally the necessary articulatory processes and their execution (air coming from the lungs, vibration of vocal chords, nasalization, point of articulation, lip rounding) to produce overt speech which takes place in close realization with monitoring of overt and internal speech allowing self-correction. "Output monitoring involves the same speech comprehension system used for listening to others" (ibid.). 
Monitoring of overt speech [and eventually writing] plays a fundamental concept in language learning. Though widely criticized, but also acclaimed by others, Krashen's Monitor Theory (1981) postulates the utterance is initiated by the acquired system and that consciously learned formal knowledge is the one which allows monitoring. In other words, the distinction between acquisition and learning is fundamental to explain potential progress in accuracy and fluency, performance variability, and interlanguage construction.

The use of the monitor (op. cit.:3) has to meet three conditions. First, the speaker needs time to apply consciously grammatical rules, something which rarely happens; second, they should focus performance on form or correctness; and third, they need to know the rule as a mental representation to apply it correctly. Krashen postulates that 'Successful Monitor users edit their second language output when it does not interfere with communication" [such] editing results in variable performance, [that is] ... different types and amounts of errors under different conditions ... [and] monitor users show an overt concern with "correct" language, and regard their unmonitored speech and writing as "careless"(ibid.: 12-13).' The above give rise to three possible L2 performers; at one extreme are monitor 'over-users' who feel rule knowledge is a must and have no trust in their mental grammar (the acquired system - the one which initiates performance) to such extent that they are afraid of speaking and making mistakes. At the other are 'under-users' who apparently depend on what they can "acquire" and seem to make no profit from error correction as a result of which their grammar is very poor. 'Optimal' monitor users, at the center of the spectrum, use conscious knowledge to control performance appropriately when it does not get in the way of communication. In other ways, unconsciously acquired L2 is supported by consciously learnt L2.

During performance the L2 learner reveals their interlanguage which consists of "... a system of implicit knowledge accounting for the apparent regularities of [their] use of the L2" (Ellis \& Barhuizen 2005: 54) which is permeable and variable. Besides, the system is affected by input as well as internal cognitive restructuring leading to use of different forms for the same grammatical structure. Being the product of different learning strategies, interlanguage is a transitional system which may develop towards native-speaker lexicogrammar patterns or fossilize.

The theoretical background above was used as the bases upon which the three cases presented below were studied and discussed.

\subsection{Three case studies}

\subsubsection{Method}

Covert recordings of the students' communication output in interaction with the teacher and monologues as well as emails and text messages were collected in order to obtain reliable samples of interlanguage. These were later transcribed and classified on a diachronic basis. The information obtained was later triangulated with the results from the students' behavior observation in class during the different stages of the learning process as well as an introspection essay on how they feel they learn and the mental processes the engage in to speak the foreign language. The cases were submitted for criticism to national and international colleagues.

\subsubsection{Cases}

Case 1

Anton is a 31 year-old Russian-ethnic born in Kazakhstan engineer in computer science with a Master's Degree in Telecommunications interested in climbing up the professional ladder and having children with his young wife. His job as a technical writer in a small local firm provides enough to live modestly and pay for his flat mortgage though not as much for his dreams to come true. He is sure part of his future is in learning English if he wants to work for an international company.

After having studied English for several years as part of his basic and undergraduate education, Anton enrolled in several courses at language schools and completed the intermediate level, though, in his own words, "I feel there are many rules I don't know to speak. When I want to tell something I can't to find the words in English." To which he added, "In the schools they teach me a lot of grammar and words. We translated a lot." A placement grammar test showed his grammar was truly intermediate although his lexical range was limited. The speaking part of the test revealed he could communicate though neither accurately nor fluently, for instance, to describe or argue. He struggled with his sentences, and sometimes his output looked like anything, but English. At that moment, ten months ago (June., 2014), after discussing his personal interests, perceived and real language needs, we decided to go over the intermediate level again to recapitulate the grammar, increase his vocabulary, get rid of his tendency to translate from Russian as much as possible and lay great emphasis on communication. 
Though still with traces of MT interference, his interlanguage is moving in the direction of native-speaker lexicogrammar (See a sample of his speech transcribed below). As a student, he dutifully does his class and homework and follows instructions, asks for clarifications when needed, note downs in English new meanings as well as information related with the use new lexicogrammar such as pronunciation, word forms, synonyms, antonyms and possible collocations. At the same time, he makes a conscious effort to use new language items in communication output. Besides, early in the course, he began reading adapted literature in English. Today, we usually discuss the news, literature, politics, economy, movies, documentary as well as incidents and opinions on www.reddit.com. In other words, he seeks contact with the L2. His short-term memory capacity in the L2 has increased significantly as evidenced by remembering specific details from a listening or comprehension tasks which he can paraphrase, seemingly, without much difficulty with the correct expressions. Anton has just begun the upper-intermediate level. His learning style and approach to communication have undergone extraordinary transformations. He no longer depends entirely on bilingual dictionaries or online translation, consciously applies communication strategies, and little by little has been able to learn how to monitor most of his output. In other words, he is becoming an optimal monitor user as the following transcribed excerpt, an opinion on a website (See Latham-Koenig \& Oxenden's English File. Intermediate Plus. Student's book. $3^{\text {rd }}$ Ed. OUP) shows.

Our family, our story and our lives are usually interesting to other people. So I think that each person, if he have ... has... a family or close friends, his memories was... will be interesting and very good for them. But about this site, StoryCorps I think that it does not work, maybe, as they want. I think, maybe, it looks like a fairy tale collection because I think nobody will say some bad things about himself if this disk ... will be ... is saved in the Congress Library. (00:00:18)

\section{Case 2}

Tanya is a medical doctor in her late-thirties specialized in aesthetic therapy who knows English and is interest in learning Spanish to communicate when she travels to Spain and Latin America with her family. She fell in love with the language after her first trip to Cuba and contacted me through a former student almost three years ago. At the beginning most of our communication was English due to my limited Russian. She is a very serious student who never fails to do a piece of homework, asks for clarification and does not attempt to do anything unless she clearly understands what she has to do. After all this time, she has almost completed the B1 level though she is not fully ready to start B2. Every three or four months she interrupts her twice-a-week lessons because of either family problems or traveling abroad for pleasure. After each of these periods, it takes her about one week or two to be in full shape to go ahead with the course.

This daughter of a now retired primary school teacher is very aware of correct language use, manages grammatical categories and functions without difficulties and is keen on understating the inner workings of syntax. Educated under the influence of former USSR language teaching methods, she relies a lot on translation for every word or expression, any of which she sometimes translates first into English and then into Russian using an online translator or a bilingual picture dictionary. At the same time, she always has at hand tables with verb tenses and conjugations in Spanish, including their translation into Russian with no differentiation as to the different meanings the same verb may connote or notes about tense uses. Despite this, she cannot use verb tenses in Spanish accurately and usually confuses verb conjugations in the indicative and subjective moods during output communication. Whenever she is struggling to find a word in her mind, she always emits a 'brrrrrrr' sound. Tanya approaches language learning as an intellectual task though she has been advised what to do to learn more efficiently.

Apparently, traveling to Spanish-speaking countries has not been used as acquisition opportunities and, thus, had little or no effect at all in comprehension and speaking skills. "I am afraid of making mistakes when I speak." she recently told me after being in Barcelona for two weeks. She added, "It takes me a lot of time to say something correctly. I need to be sure of what I am saying." She also complains the Spanish and Cubans speak too fast. In other words, Tanya is a monitor 'over-user'. The speech excerpt transcribed below shows she is thinking in either English or Russian to translate then into Spanish and at the same time trying to monitor her output.

Teacher: "Te robaron en Cuba? (Were you robbed in Cuba?)

Tanya: Sí, jajaja (yes, hahaha)

Teacher: ¡Qué pena! ¿Qué pasó? (I feel ashamed! What happened?)

Tanya: Brrrr (usual sound when she does not find a word or expression)

Teacher: En el hotel? En la calle? (At the hotel? In the streets?) 
Tanya: No, no, no ...dance hall

Teacher: En una discoteca? (In a disco?)

Tanya: No, no, no. It's not discoteca, it's show.

Teacher: Sí, en un espectáculo artistico. (Yes, in an artistic show)

Tanya: In Gavana. (In Havana)

Teacher: Comprendo. En un show en la Habana, en Tropicana? ¿Qué te pasó en Tropicana? (I understand. In an artistic show in Havana. In Tropicana? [a world-famous nightclub] What happened to you in Tropicana?)

Tanya: Cuando gente ... fue a bailar (when people ... went to dance)

Teacher: ¿Dejaste algo en la mesa? (Did you leave anything on the table?)

Tanya: Small bag

Teacher: ...dejaste una cartera pequeña en la mesa (you left a small bag on the table)

Tanya: Nyet, sumochka. Un bolso pequeño con fотокамara, telefono mobile, dinero no mucho, cuando devolvió ... mi ... sumka ... no sé. (00:02:54) (No, bag with a camera, a mobile and money not much, when gave back ...my ...bag ... I don't know)

\section{Case 3}

Mihail is a 46 year-old $\mathrm{PhD}$ in Philosophical Sciences who, as the marketing director of a big Russian international company with business in the country and abroad, was asked to improve his English communication skills. A diagnostic test applied in our first meeting revealed his grammatical competence was poor:

As for my education, I have two suggestion. The first of all, I want to remind that I need an agreement between you and me for education. It can allow me to compensate my costs. I will prepare contract. The second one is next thing. Of course I understand that I need to restore some skills and knowledges, but I want that you use cases of my work on process of education.

The email above, a reply to my suggestion to start with a pre-intermediate course, which would allow me to work with basic lexicogrammar as the basis for business English, shows he is translating from Russian into English. He was interested, he told me later, in learning 'some phrases' he could use while doing his job and answering emails.

Complying with his perceived needs but not his real ones, we began a course in pre-elementary business English supplemented with further business grammar and vocabulary mostly as homework. After a few weeks he asked me he needed some business correspondence to which we turned for a few weeks until he asked me to teach him English for negotiations. The following email shows he was making no progress long after we began our lessons: "I spoke about usual time tomorrow tonight. About your offer regarding 12 I think no. Just I will far of City."

As a student, Mihail does not pay much attention to advice on how to tackle his problem with English. Because of his workload, he has little time to do his homework, let alone seek for contact with real language use to facilitate acquisition. This Philosophy Doctor is a 'learner', not an 'acquirer' which would not wrong if he learned and consciously applied rules, something he has been strongly advised on as well as against translating but, unfortunately, does not seem to listen to. All attempts to make changes in his learning style and approach to language learning as well as raising his language awareness have been wasted time.

Educated in the Soviet tradition, he relies on his memory, does not take notes and is even reluctant to write when asked to do so. He often makes use of the 'trial and error' method to answer comprehension exercises. Even when given the chance to monitor his output, he does not do so. The excerpt below is part of his answer to an email (See Lowe \& Pile's Negotiating (2007). DELTA publishing, ex.1 p. 27):

Thanks for your interest and desire to provide us by the best way of moving. I see you wants to present common viewpoint of some members of team. That sounds reasonable that we should take accounts positions of all members of team. On the other side that we need to make a choice and possible regret of part of our habbits......as to using I believe quite room....

As a language learner, Mihail is an 'under-user'. His spontaneous output communication is inaccurate, revealing his interlanguage is fossilized, while his reliance on translation dramatically affects fluency as the 
transcribed speech excerpt below shows. The name of the country where the event took place has been removed for ethical reasons.

Last month I took part ...ehh... in negotiations with ${ }^{* * * * *}$ producer of spare parts and this ...ehh.. meeting, spare parts in cars and the matter is that ... ahh...there are many kind sorts of spare parts and the is most effective spare parts is iridium spare parts and we ...ehh...produce ...eh.. iridium components for electrode in spare parts. The meetings was organized by Russian trade representation in ${ }^{* * * * *}$. We visited to office of ${ }^{* * * *}$ manufacturer of spare parts and before the negotiations, I have known facts about this company. The first one is ...eh.. this producer makes spare parts under license Bosch company. Bosch Company is biggest manufacturer of spare parts in all over the world. Bosch has enterprises in Germany, in China, in USA and in Russia. And also this ${ }^{* * * *}$ company also produce spare parts under license.., under Bosch license and I have known this fact and also and I decide to use this information in my negotiation because ...ehh...during two years we negotiate with German and Russian Bosch about deliveries of iridium components for spare parts....(00:03:06)

\subsubsection{Discussion}

As students Tanya, Anton and Mihail have different types of motivation. Her interest in Spanish culture and life as well as her own desire to study the language makes Tanya an intrinsically integrative motivated student whereas Anton and Mihail's is instrumental. However, Anton's motivation is intrinsic and Mihail's, extrinsicnot a very good predictor of success. These differences may, in part, explain their efforts to achieve their personal objectives if two other factors are added to the equation: professional ambitions and income. Though intrinsic integrative motivation is a predictor of success, Tanya has all the time of the world to learn Spanish, at her own pace. She need not worry about expenses for private tuition because her private practice pays well. Mihail is just doing what his company told him to do and pays for. His education, experience and history make him an asset for the company which in many cases uses one of the representatives abroad to act as an interpreter when the business partner does not know Russian. Anton, on the contrary, is still building his career, has many professional and life ambitions and is pressed by his economic situation, all of which, apparently, have lowered his 'affective filter'-in Krashen's terms, opening the way for strategic learning. Educated under the former Soviet Union foreign language method, Tanya and Mihail have not yet realized the need to change their learning style and approach to language learning to progress while Anton has.

Therefore, in the new learning conditions where translation from the L1 has been judiciously limited as well as theory-laden illustrations, both Tanya and Mihail still apply previously acquired behavior to learn. The former, to a much greater extent than the latter and because of her characteristic monitor overuse, still relies on grammatical knowledge of forms, not use, and at times demands thorough explanations of specific grammar items that are later organized in the form of algorithms and tables with the corresponding translation, something she also does for new words as well as for the old ones she does not remember. Though not as careful as Tanya, Mihail is immune to any form of grammatical correction, entirely disregards lexicogrammar forms and use and writes down the translation of every word and expression, especially those not related to his job, so as to remember them, hoping unsuccessfully to have them at hand when he needs them. Anton, on the other hand, has been able to learn new ways to learn and modify his acquired behavior. In the new conditions, he has consciously learnt the rules, is learning how to monitor output and does not rely much on translation.

Tanya's and Mihail's acquired behavior may actually influence their progress especially accuracy and fluency as the interlanguage samples show. If during unprepared spoken communication, consciously learnt L2 grammar, given the ideal conditions, subconsciously monitors output acting as an editor, the more the student resorts to translation the more accuracy and fluency are affected because of the quality of the psycholinguistic processes involved. Their potentially active psycholinguistic operations during L2 communicative output are hypothesized below based on the application of the Theory of Semantic Networks and Levelt's model for spoken language production.

During the conceptual preparation phase, these learners who rely on translation as their first communication tool elaborate the message in the L1 and start looking for the corresponding the lexical items in the L2. As these are organized in hierarchical form in semantic networks, it follows that during the learning process any L2 lexical item was assigned to an L1 network. Therefore, as the aforementioned students usually focus on one word meaning, but disregard other essential aspects of a word such as derivations and inflections, their choosing of the L2 lemma in many cases hampers grammatical encoding. It could be hypothesized that when choosing the lemmas, the learners select the ones from more accessible nodes in Russian and their closest translation into the L2 to build their own syntactic patterns in the L2, which are often quite similar to, if not the same as, those of the L1. This may explain, for instance, lack of articles or incorrect verb patterns among other problems in the students' interlanguage as a result of wrong lemma code activation during morpho- 
phonological encoding. In other words, the result of the psycholinguistic processes as described above is quite often inaccurate overt speech during phonetic encoding. However, these processes are also responsible for another effect on overt speech: lack of fluency.

Tanya, the monitor 'over-user', is so worried about editing her speech that she can hardly produce a sentence fluently. That is, she spends too much time finding the translated correct lemmas and putting them into the Spanish syntactic frames that she hardly utters a full idea. While she is translating the L1 generated message, choosing L2 lemmas and encoding them morpho-phonologically, her editor is also working. As she is not sure about what she is going to say, Tanya usually uses either a Russian or an English word because she cannot find the correct L2 form in her semantic networks. In other cases, she emits the 'brrrr' sound, she knows the lexicogrammar is there but cannot find it. Mihail, on the other hand, does not "care about grammar". As an 'under-user' he speaks as he has translated hoping what he has said is correct. However, it takes him too long to produce a full logical idea (almost a word per second in his interlanguage sample) that one may actually lose track of what he is actually saying. In other words, the more the student needs to translate the more fluency is affected. Though his English is far from accurate, Anton is on the way to become an optimal monitor user as his interlanguage sample show.

Five years of experience in the Russian foreign language teaching context allow the author to assert that solving the students' overreliance on translation processes to learn the L2 depends on the teacher's ability to identify early this problem as the cause of lack of progress and the student's willingness to test other learning approaches. Teaching the student how to learn the rules and use them according to a given context to mean may be accomplished if enough practice and opportunities to communicate are provided to foster acquisition processes At the same time, contact with L2 use enhances the possibilities to increase language awareness by comparing the L1 and L2 structural similarities and differences as well as meaning making mechanisms between the two languages. Discouraging translation, on the other hand, will only be successful if the student realizes how much harm it can do and actively engages in monitoring their output. Rather than the traditional error correction teacher approach where the teaching provides the correct target language forms, the student must learn how to correct themselves. Output monitoring concerns not only forms but also meanings in context. It may take the student a long time to achieve this; however, analyzing critically and correcting their own writing or recorded speech is a worthwhile effort in terms of learning results.

\section{CONCLUSIONS}

Though Russian foreign language students are not the only ones in the world who largely depend on the L1 to learn and use the L2, reliance on translation processes can be traced back to traditional practices and beliefs, derived from almost sixty-year old research in psychology, transmitted from the teacher to the learner resulting in classroom-modeled ingrained learning habits. Nevertheless, these habits may be changed, a question which rests on the teacher's skills to influence the student as well as their willingness and actions. The case studies presented corroborate how overreliance on translation impairs accuracy and fluency during communicative output because of the quality of the psycholinguistic processes involved. The conceptualization of those processes, however, needs further validation. On the other hand, it seems that given the proper guidance and means, L2 learners may actually learn how to monitor their output.

\section{REFERENCE LIST}

Carroll, D. W. (2008). Psychology of Language. $5^{\text {th }}$ Ed. Belmont: Thomson Wadsworth.

Celce-Murcia, M. \& Larsen-Freeman, M. (1999). The Grammar Book. Heinle \& Heinle.

Celce-Murcia, M. (1991). Grammar Pedagogy in Second and foreign language teaching. Tesol Quarterly. 25 (3), 459-480.

Cook, V. (2008). Second Language Learning and Language Teaching. $4^{\text {th }}$ Ed. Hodder Education.

Dagiliene, I. (2012). Translation as a learning method in English language teaching. http://dx.doi.org/10.5755/j01.sal.0.21.1469

Duyck, W. \& Warlop, N. (2009). Translation priming between the native language and a second language. New evidence from Dutch-French bilinguals. Experimental Psychology. 56(3), 173-179.

El-dali, Hosni. M. (2011). Re-examining the influence of native language and culture in L2 learning: A multidisciplinary perspective. At: www.humanicus.org/global/issues/humanicus.../humanicus-6-20112.pdf. 
Ellis, R. \& Barkhuizen, G. (2005). Analising Learner Language. Oxford: OUP.

English proficiency index. Available at: https://www.ef.com/epi. [Accessed 01/06/2015].

Forteza, R. (2015). Towards a form choice context-mediated meaning-making EFL learning. To appear in: Pedagogicheskii jurnal Bashkortostana, № 4 (59).

Glyn Lewis, E. (1962). Foreign and second language teaching in the USSR. The British Council. ETIC ocassional paper (1).

Halliday, M.A.K. (1985). An Introduction to Functional Grammar. $2^{\text {nd }}$ Ed. London: Arnold.

Hassan, R. (2009). "The place of context in a systemic functional model". In Halliday, M.A. K. \& Webster, J. (Eds.) Continuum companion to systemic functional linguistics (pp. 166-189). London: CIPG.

Ivanova, M.E. (2010). Gramatika Angliiskogo. Eto Trudno? Moskva: Pero.

Karpov, I. \& Mirolubov, B.(1957). Sorok let sovetskoi metodike prepodavaniya inostrannyx yazykov. Inostrannye yazyki $v$ shkole, 5 .

Krashen, S. D. (1981). Second Language Acquisition and Second Language Learning. Pergamon.

Larsen-Freeman, d. (2009). "Teaching and testing grammar". In M. Long and C. Doughty (Eds.). The Handbook of Language Teaching (pp. 518-542). Malden, MA: Blackwell.

Leow, R. P. (2007). "Input In The L2 Classroom. An Attentional Perspective on Receptive Practice". In R. Dekeyser (Ed.). Perspectives from Applied Linguistics and Cognitive Psychology (pp. 21-50). NY: CUP.

Levelt, W. (1999). "Producing Spoken Language: A Blueprint of the Speaker”. In C. M. Brown \& P. Hagoort (Eds.). The Neurocognition of Language (pp. 83-122). Oxford: OUP.

Litvinov, P. (2004). Angliiskie glagoly I prilagatelhye s fiksirovannymi pridlogami. Moskva: Airi press.

Mahmoud, A. (2006). "Translation and Foreign Language Reading Comprehension. A Neglected Didactic Procedure". English Language Teaching Forum, 4, 28-40.

Malmkjaer, K. (1990). Translation and Language Teaching. Manchester: St. Jerome.

Mustlaq Al-zu'be, M.F. (2013). "Foreign Language Teaching and Translation". Research on Humanities and Social Sciences. 3 (9), 27-31.

Nunan, D. (1988). "Teaching Grammar in Context”. ELT Journal. 52 (2), 101-109.

Nunan, D. (2015). Teaching English to Speakers of Other Languages. An Introduction. NY: Routledge.

Nuzhdin, G.; Marin, C. \& Martin Lora, P. (2008). Español En Vivo. Moskva: Airis Press.

Petrina, P. Curriculum and Instruction for Technology Teachers, Chapter 4. Available at: http://people.uwplatt.edu/ steck/Petrina\%20Text/Chapter\%204.pdf.

Rogova, G.V. (1975). Methods of Teaching English. Leningrad.

Rogowski, B. Calhoun, B.; Tallal, P. (2015). "Matching Learning Style to Instruction Method: Effects on Comprehension". Educational Psychology. 107 (1), 64-78.

Soloviova, E. H. (2006). Metodika Obucheniya Inostrannym Yazykam. Bazovyi Kurs Lekcyi. Moskva: Prosveschenie.

Stepukina, T.V. (2013). "Aims and Content of Foreign Language Teaching in Ukraine in the 1950s and 1990s". Teaching English for Specific and Academic Purposes, 1(2), 135-142.

Ur, P. (1988). Grammar. Cambridge: CUP.

Zikova, G. et. al. (2006). Angliiskii Yazyk Dlya Studentov Yaziykoviyx Vuzov. Vtoroi Etap Obucheniya. Astrel. 